\title{
Reforma Psiquiátrica e Transição Paradigmática no Interior do Estado de São Paulo ${ }^{1}$
}

\author{
Daniel Mondoni² \\ Abílio da Costa Rosa \\ Universidade Estadual Paulista “Julio de Mesquita Filho" (UNESP), Campus de Assis
}

\begin{abstract}
RESUMO - Este trabalho investiga o aspecto qualitativo da Reforma Psiquiátrica no interior do estado de São Paulo, por meio da análise dos discursos presentes no campo da Saúde Mental. Balizamo-nos no referencial da Atenção Psicossocial enquanto corpo teórico-prático e ético para transformação paradigmática em Saúde Mental. Como método, utilizamos entrevistas semidirigidas com coordenadores de CAPS e coordenadores municipais de Saúde Mental, e observações participantes, analisadas por meio do método dialético de análise de discurso. Foram encontradas três matrizes teóricas principais dos discursos (Psiquiatria Tradicional, Psiquiatria Preventivo-Comunitária, Atenção Psicossocial) coexistindo no espaço institucional. A vertente Preventivo-Comunitária mostrou-se bem instalada e superando técnica e teoricamente a Psiquiatria Tradicional, porém dificultando o avanço da Atenção Psicossocial em termos éticos.
\end{abstract}

Palavras-chave: reforma psiquiátrica; paradigma; saúde mental; políticas públicas.

\section{Psychiatric Reform and Paradigmatic Transition at São Paulo Countryside}

\begin{abstract}
This article investigates the Psychiatric Reform's qualitative aspect at São Paulo countryside by analyzing the discourses in the Mental Health field. This work is based on the Psycho-Social Attention referential as a theoretical, practical and ethical framework for the paradigmatic transformation on Mental Health. With respect to the methodology, we applied semi-directed interviews to CAPS coordinators and municipal Mental Health coordinators, and also performed participative observations, which were analyzed through the dialectical method of discourse analysis. It was observed three main theoretical discourses' streams (Traditional Psychiatry, Community-Preventive Psychiatry and Psycho-Social Attention) coexisting at the institution. Community-Preventive Psychiatry has been well established, but although it is overcoming some technical and theoretical constraints of Traditional Psychiatry, it is also imposing some difficulties to the ethical advances of Psycho-Social Attention.
\end{abstract}

Keywords: psychiatric reform; paradigm; mental health; public policy.

Apesar das dificuldades acarretadas pela metodologia científica médica, a psiquiatria desenvolveu seu paradigma em torno da hipótese causal somática, das medicações e das internações especializadas como forma de tratamento. Essa última institucionalizou a relação do profissional com a doença mental enquanto única forma de extrair o conhecimento socialmente reconhecido como competente. A ineficácia desses métodos, entretanto, ficou patente a partir da década de 1950 (Amarante, 1996, 1995, 1999; Costa, 1981).

No Brasil, após forte processo de privatização e hospitalização da doença mental nas décadas de 1960 e 1970, seguiu-se o início das Reformas Sanitária e Psiquiátrica. Acerca da Reforma Psiquiátrica brasileira encontramos variações quanto ao local e à data de seu início, devido a controvérsias relativas à sua concepção: se são simplesmente as primeiras transformações das práticas psiquiátricas, ou as primeiras sob os significantes "Reforma Psiquiátrica". Porém,

1 Esta pesquisa foi realizada com o apoio financeiro do Conselho Nacional de Desenvolvimento Científico e Tecnológico (CNPq).

2 Endereço para correspondência: Rua Major Solon, n 441, Apto. 41, Cambuí. Campinas, SP. CEP 13024-090. E-mail: danielmondoni@ yahoo.com.br. em todos os casos, essas transformações estão associadas a movimentos de trabalhadores da área e pretendem atingir diversas áreas sociais, não apenas os serviços de saúde. As novas práticas, teorias e ideario organizam-se em torno da Atenção Psicossocial enquanto corpo teórico-técnico-ético (Amarante, 1996, 1995, 1999; Costa-Rosa, 1987, 2003).

\section{A Reforma Psiquiátrica no Estado de São Paulo}

Ao avaliar a Reforma Psiquiátrica no estado de São Paulo, objeto de nossa pesquisa, devemos considerar a forte influência exercida pela Medicina Comunitária e sua vertente psiquiátrica, a Psiquiatria Preventivo-Comunitária, nas políticas públicas desse estado a partir do final da década de 1960. Data dessa época a criação dos primeiros dispositivos extra-hospitalares de assistência em Saúde Mental no Brasil, de características ambulatoriais e de "ação comunitária" (Costa-Rosa, 1987; Birman \& Costa, 1994). Mesmo sem sustentabilidade política, o que impediu que as transformações quanto às internações psiquiátricas chegassem a termo, foi possível que 17 Centros Comunitários de Saúde Mental fossem instalados no estado, em parceria com universidades e faculdades. 
Entretanto, a persistência e intensificação de diversos fatores como as péssimas condições dos hospitais psiquiátricos, tanto privados quanto públicos, os altos índices de cronificação, de internações e reinternações, e também os evidentes maus tratos que levaram a óbitos injustificáveis, fizeram com que a eficácia, a eficiência e os reais propósitos dessas instituições fossem questionados novamente com veemência e em tom de alarde de calamidade pública (Cerqueira, 1984).

Passados poucos anos, ao final da década de 1970, já no contexto de redemocratização do país, o movimento pelas mudanças na assistência em Saúde e Saúde Mental foram retomados, em conjunto com movimentos sociais de usuários e familiares, promovendo transformações em seus diversos setores e culminando na formulação do Sistema Único de Saúde (SUS) ao final da década de 1980. É nesse novo contexto que ressurgem propostas inovadoras para a Saúde Mental no Brasil. Propostas que, em vários estados, e particularmente no caso de São Paulo, passaram pela reedição da Psiquiatria Preventivo-Comunitária, promovendo principalmente a implantação de ambulatórios especializados. Apenas posteriormente surgem propostas na direção de sua superação e de orientação nitidamente antimanicomial, como o Centro de Atenção Psicossocial (CAPS) Luis da Rocha Cerqueira, na cidade de São Paulo em 1988, e o Núlcleo de Atenção Psicossocial (NAPS), na cidade de Santos em 1989.

Efeitos concretos fundamentais da Reforma Sanitária na política nacional de saúde, principalmente a implantação do SUS, produziram uma série de transformações importantes que foram automaticamente transpostas para o campo da Saúde Mental, introduzindo, assim, uma nova dimensão no processo da Reforma Psiquiátrica.

Merece destaque a territorialização dos serviços, estratégia fundamental para a reorganização das ações, tanto para a Reforma Sanitária como para a Reforma Psiquiátrica. Essa proposta procura aproximar, integrar e vincular afetivamente os equipamentos e trabalhadores da Saúde às pessoas e comunidades, e priorizar práticas de promoção, prevenção e educação em Saúde, visando romper com a centralização hospitalar e ambulatorial e com a inércia das práticas curativas. A territorialização, cujo corolário é a integralidade, como síntese que se opõe dialeticamente à ação fragmentadora dos especialismos, tem ainda um desdobramento que é caro para lidar com o sofrimento psíquico: a consideração do vínculo terapêutico em sua dimensão transferencial, como radicalmente necessário ao manejo dos processos de promoção-adoecimento-atenção, onde eles realmente se manifestam - nos indivíduos e grupos. Sem a criação desses vínculos, dificilmente se escapa às prescrições pedagógicas e às proposições autoritárias ou mesmo caritativas (CostaRosa, Luzio \& Yasui, 2003).

Finalmente, é necessário destacar, das contribuições da Reforma Sanitária para a Reforma Psiquiátrica, todas as proposições jurídico-políticas capazes de sustentar um conjunto de práticas de cogestão e autogestão, também no campo da atenção ao sofrimento psíquico. A própria diretriz do vínculo como fundante das ações de atenção depende, em essência, das proposições da Reforma Sanitária.

\section{Paradigmas e Transição Paradigmática no Campo da Saúde Mental}

Instalada a Reforma Psiquiátrica e já tendo produzido certo avanço na criação de dispositivos institucionais e meios teórico-técnicos e éticos de ação, chegamos à configuração de dois modos bem distintos de conceber e produzir práticas de ação junto aos sujeitos do sofrimento psíquico, como extremos de um contínuo de variações. Partindo de uma análise desses dois modos de produção, em termos paradigmáticos, Costa-Rosa $(2000,2006)$ sugere a designação, por um lado, de Paradigma Psiquiátrico Hospitalocêntrico Medicalizador (PPHM) para o modo dominante, historicamente tributário das práticas enclausurantes, medicalizadoras, e centrado em uma ação sobre a doença mental entendida como objeto empírico de fundamento orgânico. E, por outro lado, a denominação de Paradigma Psico-Social (PPS) para o conjunto das práticas que pretendem superar o PPHM, contrapondo-se ideologicamente, na teoria, na técnica e na ética.

A partir das concepções de diversos autores que procuraram aprofundar a discussão do conceito de paradigma (Kuhn, 1978; Pain \& Almeida Filho, 2000) e também a partir da influência das contribuições da Dialética e da Saúde Mental Coletiva, Costa-Rosa (2006) propõe a conceituação dos paradigmas no campo da Saúde Mental como:

conjuntos articulados de valores e interesses que se estratificam, criam dispositivos (leves ou pesados) e podem chegar à polarização. Situação em que fica indisfarçável sua função de peças na estratégia de hegemonia de subconjuntos de interesses e valores sociais especificos. (p. 18)

A estruturação de um paradigma emergente, enquanto estratégia ideológica de determinado grupo social, portanto segmentar, já traz consigo simultaneamente o paradigma oposto, enquanto seu complementar. Assim, a transição paradigmática se colocaria como o processo de luta desses dois paradigmas pela hegemonia no campo em questão, passível de análise por meio da decomposição em seus componentes. No caso presente, estudamos os modos de produção e as relações entre o PPHM e o PPS. Costa-Rosa (2006) propõe que esses paradigmas sejam compostos por, no mínimo, quatro parâmetros básicos: (I) Concepção do "objeto" e dos "meios" teórico-técnicos, referente aos modos de concepção dos processos de produção de saúde-adoecimento-atenção; (II) Modos de organização das relações intrainstitucionais e interinstitucionais como um fator essencial das relações intersubjetivas possíveis, ou seja, do modo de produção de saúde e subjetividade; (III) Modos de inter-relação instituição-clientela, população e território, isto é, modos de produção-reprodução do aparecimento da demanda e das expectativas de resposta disponíveis (representação social das formas de adoecer e das formas de tratamento à disposição no Território); (IV) Finalmente, modos dos efeitos típicos da instituição em termos de performance terapêutica e ética, ou seja, como são produzidas, em retorno das ações de Atenção, as formas de relacionamento dos sujeitos com os fatores socioeconômico-culturais do adoecimento e com a própria capacidade desejante, supostamente posta em xeque pelo sofrimento psíquico intenso. 
Ao se considerar o PPHM como o paradigma hegemônico no campo da Saúde Mental, a transição paradigmática para o PPS se daria por meio de transformações significativas nos parâmetros acima propostos (Costa-Rosa, 2006), indicando importantes sinais de transformação, mas sem chegar, ainda, a mudar radicalmente a natureza de seus efeitos. A transformação ou revolução paradigmática prevê mudanças radicais que superem dialeticamente as concepções teóricas, técnica e éticas e as práticas do PPHM, e as substituam por concepções e práticas do PPS. Em nossa pesquisa, tentamos analisar, a partir desses parâmetros, as características principais das mudanças designadas pelos termos Reforma Psiquiátrica, no interior do estado de São Paulo.

Portanto, o PPS enquanto proposta de transformação da assistência em Saúde Mental se define em oposição ao Paradigma Psiquiátrico, procurando desinstitucionalizar esse modo de conceber a loucura e suas técnicas de produção de atenção. Caracteriza-se como uma composição de diversos campos teóricos e experiências concretas de reforma ou contestação do PPHM, influenciado também pelo contexto social e histórico em que surgiu e se desenvolveu a Reforma Psiquiátrica brasileira. O PPS é tributário dos principais movimentos internacionais, tais como a Psicoterapia Institucional e a Psiquiatria de Setor (França), as Comunidades Terapêuticas e a Antipsiquiatria (Inglaterra), a Psiquiatria Preventivo-Comunitária (EUA), a Psiquiatria Democrática Italiana (Itália). Esses movimentos influenciam os métodos clínicos, a organização institucional e os fundamentos éticos e ideológicos do PPS (Fleming, 1976). O PPS procura ainda transitar por outros campos do saber humano (Filosofia da Diferença, Filosofias da Existência, Materialismo Histórico, Psicanálise, Esquizoanálise), por procurar compreender o sofrimento psíquico em sua complexidade, em suas relações com o campo social e suas instituições, com a produção material e subjetiva, tentando implementar uma prática inter ou até mesmo transdisciplinar, procurando não priorizar um saber específico a priori e focalizar o sujeito do sofrimento (Costa-Rosa, 2000, 2006).

Nas últimas décadas e, principalmente, no início da atual década no Brasil, algumas transformações foram finalmente incorporadas à Constituição, no capítulo referente aos direitos do sujeito do sofrimento psíquico, e também no modo de organizar as instituições de Atenção em Saúde Mental, redirecionando o modelo assistencial (Amarante, 1996; Luzio, 2003; Ministério da Saúde, 2004).

Tendo em vista tais processos de transformação no âmbito da Saúde e da Saúde Mental, objetivamos, com esta pesquisa, analisar como se compõe atualmente o jogo de forças institucionais em termos paradigmáticos na assistência em Saúde Mental no interior do estado de São Paulo, dada a importância histórica desse estado para o atual contexto de transformações das práticas de atenção ao sofrimento psíquico no Brasil. Nos municípios pesquisados, realizamos entrevistas com gestores municipais de Saúde Mental $^{3}$ e com coordenadores de CAPS. Também realizamos observações das práticas institucionais, procurando analisá-las frente

3 Também chamados, em alguns municípios, de 'articuladores municipais de Saúde Mental'. aos paradigmas atualmente presentes nesse campo. Procuraremos discutir nossas questões e hipóteses por meio do método dialético de análise de discursos, por entendermos ser esse o melhor meio de analisar as instituições conforme as entendemos - enquanto palco de lutas e lugar de sustentação das contradições presentes no campo social. Esse método também é capaz de desvelar o contexto de formação do discurso e suas reais significações, bem como a relação entre discurso e práticas (Costa-Rosa, 1987).

\section{Método}

\section{Participantes}

Nossa pesquisa tomou como ponto de partida as instituições que se apresentam sob os significantes Centro de Atenção Psicossocial (CAPS), no interior do estado de São Paulo. Trabalhamos em desdobramento dos resultados de uma pesquisa anterior (Devera, 2005) que tomou todo o referido território como foco de estudo. A partir da análise de Devera acerca dos discursos e de uma série de dados quantitativos sobre a rede assistencial em Saúde Mental no estado de São Paulo, pudemos observar que há um conjunto importante de transformações no campo da Saúde Mental Coletiva, resultantes de heranças diretas da Reforma Sanitária, aparentemente não devidamente dimensionadas e reconhecidas pela Reforma Psiquiátrica. Mudanças que se apresentam como transformações do campo geral da assistência à Saúde, portanto não especificamente da Saúde Mental, e que, mesmo fundamentais na legislação e no ideário, não necessariamente indicam mudanças nas práticas e nos parâmetros paradigmáticos do PPHM.

Tomamos alguns municípios para uma análise mais acurada, visto que uma série de fatores nos permitiu formular a hipótese de que, se não há transformação radical do PPHM, ao menos é pertinente esperar uma transição paradigmática na direção do PPS, ou seja, mudanças importantes em parâmetros do paradigma no sentido de sua transformação (Costa-Rosa, 2006; Devera, 2005).

Seis municípios de grande porte (acima de $200 \mathrm{mil}$ habitantes) foram incluídos na pesquisa, de acordo com os critérios considerados por Devera (2005) como indicadores de maior possibilidade de transição ou transformação paradigmática (grande porte populacional, gestão plena dos recursos para a Saúde, contando com equipamentos da Atenção Psicossocial como CAPS ou NAPS). É necessário assinalar, de imediato, que apesar de todos os municípios terem porte para implantação de CAPS III, encontramos os três níveis institucionais de CAPS. Consideramos esse dado importante, já que apenas o CAPS de nível III dispõe de leitos para acolhimento noturno e também devido a composição das equipe dos serviços visitados variarem em número de profissionais de acordo com o nível institucional. Encontramos também outros equipamentos de assistência à Saúde Mental nesses municípios e sua presença, função e utilização serão levados em conta no momento da análise. 


\section{Procedimento}

Utilizou-se o método de entrevistas semi-dirigidas, propondo-se ao entrevistado que falasse livremente acerca de determinados temas. Coube ao entrevistador fazer questionamentos e apontamentos que causassem a ampliação da argumentação do entrevistado quanto aos temas. Em cada município, foram realizadas duas entrevistas. A primeira com o gestor municipal de Saúde Mental e a segunda com o coordenador de um CAPS, totalizando 12 entrevistas para o trabalho. Além das entrevistas, também foram feitas observações participantes do cotidiano institucional e das atividades em cada CAPS visitado.

Concebemos a instituição como uma formação material constituída de saberes e práticas articulados por um discurso ideológico, portanto lacunar (Costa-Rosa, 1987). Lacunar porque o discurso é uma produção coletiva que tenta homogeneizar os objetivos e funções institucionais, os interesses, valores e ideais diversos e divergentes do campo social, em torno dos interesses e ideais de um único grupo, de modo que pareçam de toda a sociedade, ou simplesmente de toda a instituição: eis o caráter ideológico. Mas, para isso, compromete sua lógica e coerência, ao separar os pensamentos do contexto social e histórico em que foram produzidos para que pareçam naturais, corretos e imutáveis. Portanto, o discurso é aqui visto como um fator estruturante das relações, seja entre sujeitos, seja entre estes e o próprio conhecimento. É linguagem em interação, nas suas variadas formas, verbais e não-verbais, capaz de engendrar sentidos e de construir os lugares subjetivos que dão contorno às relações sociais institucionais objetivas. São as condições de produção de um discurso, isto é, seus processos de enunciação, que definem sua significação, revelam seus mais genuínos propósitos e sua vinculação a um grupo social específico, sua falsa homogeneidade. Isso geralmente está encoberto em suas contradições, falhas e omissões, reveladoras de sentidos diferentes e mesmo opostos ao oficial.

Por considerarmos a ciência como prática social, torna-se possível condicionar seu surgimento a um período histórico e um contexto social específico; e também como toda prática social é dialógica, um meio de instauração de relações entre pessoas. A ciência como prática social coloca então a pesquisa em um novo lugar, o de intercessão, já que a partir desse ponto de vista o pesquisador, bem como seu objeto de estudo, têm papel ativo na produção do conhecimento, sendo deslocados da posição de neutralidade. Desse modo, o método dialético também tira a prática científica do lugar de produtora de verdades universais, para colocá-la de produtora de verdades em sua dimensão histórica e conjuntural.

\section{Análise de dados}

As categorias "expressas por meio de práticas discursivas, são estratégias linguísticas delineadas para conversar, explicar, organizar e dar sentido ao mundo, cujas especificidades estão vinculadas aos contextos que as produzem." (Spink, 2000, p. 79). Apresentam-se, portanto, como uma possibilidade de trabalho do pensamento para a construção e organização da realidade, já que não estão presentes objetiva- mente no campo social (Kopnin, 1978); assim sendo, podem ser utilizadas como instrumento para sua própria análise.

Em nosso trabalho, a construção de categorias teve o intuito de, entendendo o discurso como um palco de sustentação de contradições e polissemias, dar visibilidade ao jogo de forças institucionais e aos posicionamentos éticos e ideológicos do emissor da fala, procurando abrangê-lo em suas polaridades. A partir do confronto entre os sentidos oriundos do corpo teórico construído previamente por revisão bibliográfica, e daqueles surgidos durante o processo de coleta de dados, foram construídas cinco categorias de análise. Cada categoria tem por função expor os dados mais relevantes de forma organizada, ao mesmo tempo em que os analisa preliminarmente, procurando situá-los dentro da análise paradigmática a que nos propomos e expondo, ainda parcialmente, os posicionamentos intrínsecos a cada discurso. As temáticas escolhidas para cada categoria caracterizam-se por abordar de forma ampla os aspectos técnico, teórico e ético das instituições visitadas, contemplando os extremos antagônicos e suas variações possíveis, possibilitando assim a análise de cada uma e o esclarecimento de seus posicionamentos (Kopnin, 1978; Kosik, 1976; Minayo, 2000; Spink, 2000).

\section{Resultados}

A exposição e discussão preliminar dos dados coletados se dá com base em cinco categorias de análise: "territorialização dos equipamentos de Saúde", "o lugar do psiquiatra na instituição", "da relação com o Hospital Psiquiátrico e com o Ambulatório de Saúde Mental", "os modos de gestão e a rede assistencial ", e "o teor discursivo e o ideário". Como veremos, essas categorias são elementos que definem a direção da análise, dependendo o sentido dessa, do próprio sentido adquirido por cada uma delas no contínuo de possibilidades que designamos anteriormente com os termos extremos PPHM e PPS. Estão aqui incluídos os dados das observações participantes.

\section{Territorialização dos equipamentos de saúde}

Os discursos encontrados por nossa pesquisa mostram que no interior do estado de São Paulo existem desde CAPS visivelmente desterritorializados - centralizadores da demanda e descontextualizados frente à rede de assistência à saúde - até aqueles com muitas e variadas relações com o território em que estão inseridos e com outras instituições e entidades. Analisando a partir desse aspecto, parece caracterizar-se, para alguns, um processo de transição paradigmática por comportar intermediários e extremos antagônicos, considerando o conjunto pesquisado.

Os dados surgidos nas entrevistas nos permitiram inferir acerca de alguns pontos relativos à territorialização dos serviços, tais como: o posicionamento dos CAPS na rede de atenção e frente à demanda, sua capacidade de conceber parcerias no território e firmá-las efetivamente, o contato com outras instituições de saúde ou de outras secretarias municipais e com entidades da sociedade como um todo, e o local que utiliza para as internações quando necessário. 
Da perspectiva da inserção e relação dos CAPS com o território efetivo e com os conceitos de ação territorializada, pudemos observar algumas transformações importantes, porém localizadas, relacionadas com fatores aparentemente incluídos no ideário da Reforma Sanitária e da Reforma Psiquiátrica, mas ainda aparentemente bastante à mercê de características individualizadas locais. Tais transformações não nos parecem suficientes para falar em transição paradigmática quanto à ação territorializada, no interior de São Paulo. Podemos, entretanto, falar em transição paradigmática, localizada, lembrando que a "territorialização" pode ser incluída no parâmetro III do paradigma: relação instituições - território/população/sujeito do sofrimento.

\section{O lugar do psiquiatra na instituição}

O lugar que o psiquiatra ocupa no imaginário institucional, suas ações a partir daí, e o modo como decorrem as relações intrainstitucionais frente a esse posicionamento, mostraram-se reveladores da lógica paradigmática que permeia as práticas cotidianas, tais como os processos de trabalho, a noção de clínica em Saúde Mental e de Reforma Psiquiátrica.

Os psiquiatras despontaram como os profissionais com maior resistência às transformações nas práticas profissionais, talvez por tais mudanças seguirem na direção da quebra de sua velha hegemonia no campo. Procuramos analisar esse parâmetro - o lugar ocupado pelo psiquiatra nesses serviços - a partir das atividades realizadas pelo psiquiatra, suas implicações sobre a clínica e sobre a organização da instituição, o posicionamento do restante da equipe frente ao lugar assumido por esse profissional, a relação entre os aspectos clínicos e de gestão, a forma de cumprimento de sua carga horária (integral ou parcial).

Pudemos verificar que o posicionamento do psiquiatra é muito importante, pois suas condutas continuam tendo forte influência sobre as demais ações terapêuticas, mesmo quando o restante da equipe se opõe à sua forma de atuação. Essa categoria de análise tem ainda melhor ilustrada sua relevância se lembrarmos que ela remete aos parâmetros I e II do paradigma: concepção do processo saúde-adoecimentoatenção e dos meios de ação sobre esse processo; forma do organograma da instituição e modo da divisão do trabalho inter-profissional, e seus reflexos nas relações terapêuticas, intersubjetivas e socioculturais.

\section{Da relação com o hospital psiquiátrico e com o ambulatório de saúde mental}

A maneira como o CAPS e a gestão municipal se colocam frente ao Hospital Psiquiátrico e ao Ambulatório de Saúde Mental também se mostrou como um fator de análise importante. A construção das estratégias terapêuticas e o posicionamento dos profissionais junto aos usuários se mostraram fortemente influenciados por essa relação. A partir do final da década de 1980 houve no país uma forte pressão para a redução de leitos psiquiátricos, levando à ampliação da rede assistencial extra-hospitalar com a criação de novos Ambula- tórios de Saúde Mental e dos CAPS, que ainda trabalhavam conjuntamente ao Hospital Psiquiátrico. Atualmente, o modo como se articulam essas três instituições pode ser revelador do tipo de atenção prestada pelos serviços, e também de qual é o papel dos CAPS nessa rede.

A criação dessa categoria de análise se deu a partir da capacidade e da forma de acolhimento das crises nas diversas instituições visitadas, do local preferencialmente utilizado para internações, da existência e maneira de utilização de Residências Terapêuticas, dos critérios de caracterização das crises e de justificação das internações, e do lugar que o CAPS ocupa na rede assistencial.

Observamos dois modos básicos de constituição dessa rede assistencial, com diferentes implicações. No primeiro, o CAPS localiza-se como intermediário entre o Ambulatório de Saúde Mental e o Hospital Psiquiátrico. No segundo, o CAPS coloca-se como substitutivo às outras duas instituições. Essa categoria remete aos parâmetros I e III do paradigma. Com relação a ela também podemos falar de uma transição paradigmática localizada, uma vez que nesses locais a lógica do PPHM vai sendo superada.

\section{Os modos de gestão e a rede assistencial}

O posicionamento ético-político dos gestores municipais de Saúde Mental e dos coordenadores de CAPS frente à gestão dos serviços é outro fator que se mostrou como possível indicador paradigmático. Por meio dele pudemos refletir acerca do estado da democratização da gestão em Saúde em seus diversos dispositivos institucionais impressos na Constituição Federal tanto pela Reforma Sanitária quanto pela Reforma Psiquiátrica.

Eis alguns dados que nos permitiram entender o funcionamento dos serviços e suas formas de gestão: os espaços de gestão existentes e sua capacidade decisória; o posicionamento frente aos espaços coletivos; o fluxo decisório; o posicionamento de trabalhadores, coordenadores institucionais e articuladores municipais frente à gestão; o modo de organização dos processos de trabalho; e a forma de estruturação da rede assistencial.

Talvez possamos afirmar que essa categoria de análise remete a um dos aspectos em que é mais difícil caracterizar a transição paradigmática. Paradoxalmente, ainda que a Reforma Sanitária e a Reforma Psiquiátrica tenham conseguido imprimir na própria Constituição Federal os preceitos e dispositivos que garantem a cogestão horizontal entre trabalhadores, usuários e gestores nos serviços de saúde, somente isto não parece garantir o funcionamento participativo, coletivo e democrático dos espaços destinados a esta função, como conselhos, colegiados e assembléias.

Assim mesmo são inegáveis os sinais importantes, também localizados, de transição, tais como a existência de conselhos locais e colegiados gestores nos CAPS, os contatos com a Atenção Básica e outros serviços, e a própria constituição da noção e da importância de uma rede assistencial. Essa categoria pode ser remetida aos parâmetros I, II e IV do paradigma, mas é nos termos do parâmetro II - formas das relações organogramáticas dos dispositivos institucionais que ela melhor se traduz. 


\section{O teor discursivo e o ideario}

Essa categoria visa analisar o teor dos discursos em si mesmos, enquanto representantes das lógicas de pensamento explicitadas por meio dos conceitos e definições sobre os próprios campos da Saúde e Saúde Mental, enunciados nas entrevistas, a partir dos quais podemos inferir possíveis transformações discursivas no sentido da transição paradigmática no ideário e nas práticas discursivas. Foi-nos possível pensar essa categoria a partir das definições de Reforma Psiquiátrica e Reforma Sanitária fornecidas pelos entrevistados, e a forma como se referem a diversos aspectos institucionais, tais como a medicação e o Hospital Psiquiátrico.

Mesmo nas instituições em que prevalece a inércia das práticas na direção do PPHM, podemos dizer que os discursos configuram claramente um ideário em que o Hospital Psiquiátrico e sua lógica vão sendo preteridos e mesmo abolidos. Sob esse prisma é possível afirmar que a transição paradigmática apresenta-se muito mais bem configurada no ideário, ou seja, nas práticas discursivas.

As descrições feitas acima se incluem paradigmaticamente, de acordo com nosso método de análise, entre o PPHM e o PPS, este último comportando características da psiquiatria tradicional e de suas versões reformadas. $\mathrm{O}$ que não quer dizer que os discursos encontrados, ainda que possam ter uma matriz teórica que se destaque, encontrem-se bem definidos e delimitados; muito pelo contrário, mostraram-se muitas vezes contraditórios, o que é esperado devido aos variados atravessamentos ideológicos, éticos, teóricos e técnicos.

\section{Discussão}

Nesse item faremos a última análise dos dados retomando os nossos achados em relação aos objetivos da pesquisa: analisar o atual jogo de forças que influi sobre o processo da Reforma Psiquiátrica para avaliar seu andamento, procurando verificar se já podemos falar ou não em transição ou mesmo revolução paradigmática no interior do estado de São Paulo. Para isso, continuaremos a análise iniciada pela construção das categorias buscando os enlaçamentos e inter-relações entre elas, de modo a termos um conjunto mais completo do jogo de forças. Por último, as categorias serão analisadas à luz dos discursos encontrados por Devera (2005).

Ainda que possamos subdividir os discursos nas categorias apresentadas acima, fica evidente que os aspectos abordados em cada uma delas não se desenvolvem de maneira independente. Ao contrário, mantêm relações bastante estreitas entre si. A partir dos discursos, pudemos ver variados e criativos entrecruzamentos das possibilidades de posicionamento ético e político, produtores de mesclas singulares dos modelos de atenção, que tornavam cada instituição única. Porém, mesmo que essas instituições tenham parecido bastante diferentes entre si, podemos dizer que encontramos algumas com transformações em vários aspectos institucionais e da gestão municipal, que caracterizam uma tendência à transição paradigmática.

Os discursos encontrados mostram variadas matrizes teóricas e suas inter-relações dentro da mesma instituição, trazendo à tona as disputas pelo poder institucional. De um modo geral, esses discursos ainda parecem embasar-se principalmente no PPHM - preocupações tutelares, referência à incapacidade dos usuários e aos sintomas como algo ruim a ser eliminado, dependência do Hospital Psiquiátrico, caracterização dos CAPS como instituição complementar, utilização prioritária da medicação. Expressam a estratificação das instituições de Saúde em níveis hierárquicos, de acordo com sua complexidade tecnológica, e pensam o CAPS enquanto espaço físico unicamente. Isso é condizente com a vertente Preventivo-Comunitária, que se mostra muito bem instalada. Nos discursos domina a preferência pelas instituições extra-hospitalares, e a referência às internações psiquiátricas como um mal necessário. Porém, a caracterização dos CAPS como unidade complementar mantém o lugar hegemônico do Hospital Psiquiátrico e do PPHM, de seus discursos e práticas, ainda que de forma recorrentemente declarada como indesejada.

Pode-se dizer, contudo, que aqui o ideário pretende ser mais avançado que as práticas. É importante atentar para esse dado, pois como a Reforma Psiquiátrica construiu-se principalmente em oposição à Psiquiatria Tradicional, os pontos de dissidência entre ela e o modelo PreventivoComunitário são muito mais sutis. Neste, a importância declarada do Hospital Psiquiátrico e seu lugar concreto na rede assistencial são bastante distintos, porém não esqueçamos que o referido modelo tem convivido até bem com o modelo hospitalocêntrico, a que o preventivismo sucede no discurso. No discurso do modelo Preventivo-Comunitário enfatiza-se largamente a preferência por instituições extra-hospitalares, que têm como modelo os Ambulatórios de Saúde Mental, organizados em equipes multiprofissionais. Mantêm-se, porém, intocáveis, a lógica e a ética psiquiátrica, e sua função social homogeneizante e excludente, principais aspectos de divergência entre o modelo Preventivo-Comunitário e a Atenção Psicossocial. Exatamente por isso foi possível encontrar contradições mais claras entre os discursos e as práticas nas instituições atravessadas pelo preventivismo. Porém, a consequência mais danosa parece decorrer de que as diferenças entre o modelo Preventivo-Comunitário e a Atenção Psicossocial aparentemente não se constituam como oposições dialéticas, e sim como simples diferenças, o que lhes rouba a devida importância, neutralizando sua potencialidade de transformação.

Concluímos, então, que o modelo Preventivo-Comunitário apresenta-se como uma Reforma Psiquiátrica no exato sentido do termo 'reforma', uma vez que opera transformações no PPHM, mas apenas em seus aspectos secundários, aumentando sua eficiência para atingir seus fins.

Um dado importante é que as transformações institucionais que podemos considerar mudanças paradigmáticas mostraram-se estreitamente vinculadas à presença dos CAPS. Ainda que em todos os casos tenhamos encontrado aspectos ou conjuntos de aspectos que indicam tendência à transição paradigmática, é a presença dos CAPS III que parece acentuar radicalmente, e tornar ainda mais evidente, a oposição entre a Reforma Psiquiátrica/PPS e o PPHM. Nos municípios onde encontramos os CAPS III já não existiam Ambulatórios de Saúde Mental e a utilização dos Hospitais Psiquiátricos era rara, percebida como indesejada e preterida ao máximo por internações em Hospital Geral. 
A presença de CAPS I e II em municípios de grande porte populacional parece mascarar e despotencializar a própria diretriz que propõe o CAPS como substituto de Hospital Psiquiátrico, tornando-os mais passíveis de recuperação pela lógica do PPHM. O CAPS III mostrou-se capaz de maior impacto em aspectos como a gestão institucional, mudança na concepção de clínica e das relações intra-institucionais e com o Território adscrito. Isso não significa que a Reforma Psiquiátrica esteja estritamente vinculada à presença de CAPS III, como se esse processo se resumisse à instalação dessas instituições ou como se os CAPS I e II não fossem capazes de confrontar o PPHM. Todos os CAPS são peças importantes no jogo de forças e formas potenciais de superação do PPHM, dado o ideário que os sustenta, porém com efeitos diferenciados.

A presença em si dos CAPS nos municípios e o modo como se apresentam, mostraram-se resultantes das políticas federais e municipais para o campo da Saúde Mental, das relações entre essas políticas e da nova cultura em relação à loucura de um modo geral. A presença ou ausência de CAPS, ou mesmo a quantidade deles no município parece ser um efeito imediato de como cada gestão municipal se apropriou do ideário da Reforma Psiquiátrica e sua vertente da Atenção Psicossocial.

Nossa análise, em sua complexidade, parece mostrar que a transição paradigmática guarda maior relação com o processo histórico do jogo de forças e de interesses mais amplos em luta no Território, do qual os CAPS, e o modo como funcionam no município, são também um efeito. Mas, uma vez implantados, os CAPS colocam-se como peças importantes na luta por uma nova estratégia de hegemonia para o campo da Saúde Mental, com maior ou menor potência para a promoção da transição paradigmática. Vimos que quanto menor a homogeneidade, tanto nos discursos das políticas assistenciais como nos discursos institucionais, mais claras as contradições presentes nessas instituições.

Cremos estar amplamente demonstrada a pertinência de nossa hipótese inicial de que a transição paradigmática, se existente, deveria ser encontrada em municípios de grande porte populacional, com ampla gestão dos recursos financeiros para a Saúde, que lhes daria as bases para a gestão das políticas para o setor. Entretanto, vimos claramente que existem outros fatores que contribuem para essa transição, visto que ela não ocorre automaticamente. Na realidade ela ainda é bem rara. A quais outros fatores poderemos atribuí-la? Certamente estarão relacionadas às singularidades históricas locais e conjunturais como, por exemplo, relações estritas com universidades ou a presença nesses municípios de lideranças importantes do movimento da Reforma Sanitária e da Reforma Psiquiátrica.

No que se refere aos tipos de discursos encontrados, diferentemente de Devera (2005), que encontrou quatro discursos em sua pesquisa - Psiquiatria Tradicional Inalterada, Psiquiatria Preventivo-Comunitária, um discurso com influências da Reforma Sanitária e, por último, um discurso indefinido, vago, sem consistência teórica -, encontramos apenas os dois primeiros, aos quais veio se acrescentar o Discurso da Atenção Psicossocial, que configura a transição paradigmática e no qual percebemos algumas influências da Reforma Sanitária (valorização da territorialização e das formas de cogestão). Pudemos perceber o quanto o discurso da Psiquiatria Tradicional vem perdendo terreno para sua vertente reformada, a Psiquiatria Preventivo-Comunitária, às vezes aparecendo como sua tradução. Parece-nos que o enclausuramento medicamentoso vem se sobrepondo ao físico devido à impossibilidade de contenção física desses espaços, os CAPS, ao mesmo tempo que condiciona boa parte dos demais processos de trabalho da equipe; enquanto isso os Hospitais Psiquiátricos ganham cada vez menos apoio, sendo considerados como um "mal necessário", porém ainda indispensável. A Psiquiatria Preventivo-Comunitária mostrou-se capaz de, ao mesmo tempo, superar aparentemente as práticas psiquiátricas tradicionais, por meio da alocação dos serviços no Território, porém mantendo seus interesses e valores intactos, e ainda velando os discursos favoráveis a transformações mais radicais. Nossas observações indicam que, em alguns dos municípios visitados, a superação da Psiquiatria Preventivo-Comunitária parece ser o novo passo para a Atenção Psicossocial. Talvez possamos ainda considerar que o fato da Reforma Psiquiátrica não tirar as principais consequências das conquistas da Reforma Sanitária aparece como um dificultador para isto.

Quanto à nossa hipótese sobre a transição paradigmática, pudemos ver como o desenvolvimento de políticas e estratégias de saúde, incluindo a própria instalação dos CAPS III, propiciou espaço para novas articulações entre saberes, práticas e discursos, produzindo amplos efeitos tanto na instituição quanto no Território e na gestão municipal, com a quebra da hierarquização das instituições de Saúde e com a constituição de parcerias em uma rede planificada de assistência. Tais transformações vão ao encontro das propostas da Atenção Psicossocial, ao mesmo tempo que rompem com a Psiquiatria Preventivo-Comunitária. Nesses casos, vemos como as políticas de Saúde Mental são apenas parte de um conjunto maior de transformações para todo o campo da Saúde, que normalmente inclui a valorização, complexificação e ampliação da rede de Atenção Básica.

Podemos dizer que nos municípios com CAPS I e II existem transformações paradigmáticas parciais, mas apenas em alguns aspectos dos componentes, dificilmente neles como um todo. Os discursos, práticas e saberes com potência para transição, encontram-se, pois, desarticulados, fragmentados e isolados na instituição e na rede assistencial. Ganham, então, a característica de trabalhos individuais, centrados em profissionais ou grupos de profissionais específicos, não se definindo, portanto, como construção coletiva; daí também a desvalorização de espaços como reuniões de equipe, assembléias, conselhos gestores entre outros.

Nos municípios e instituições em que há CAPS I e II, geralmente encontramos transformações nas concepções de "objeto", dos "meios" teórico-técnicos de ação e da produção do processo saúde-adoecimento-atenção; é importante notar que tais mudanças, na maioria das vezes, restringem-se ao interior da instituição. Esses serviços conseguem também promover mudanças nos modos de organização das relações intrainstitucionais e da instituição com a clientela, procurando certa horizontalização. Porém, há muita dificuldade de transpor os limites da instituição, suas práticas e discursos, como se a Reforma Psiquiátrica fosse o CAPS, e este se restringisse ao seu espaço físico, dificultando intervenções na produção 
cultural e nos processo de subjetivação de forma ampla. Isso ocorre porque essas instituições colocam-se como o eixo organizacional e porta de entrada dos serviços de Saúde Mental no município, conforme o define a legislação, sem ter capacidade para assistir todo o território que é posto sob sua responsabilidade.

Alterações na direção do PPS, mesmo que de modo restrito e localizado, puderam ser observadas nos casos em que esses CAPS conseguem territorializar-se no município, evitando assim o afogamento pela demanda espontânea, conseguindo atuar exteriormente ao CAPS - realização de visitas domiciliares, Oficinas Terapêuticas externas, acompanhamentos terapêuticos e incentivos à inclusão social, mostrando indícios de mudanças nas relações interinstitucionais, com a população e com o Território. Porém, tais alterações continuam restritas e limitadas ao âmbito das políticas municipais. Esse avanço para o exterior parece decorrer da continuidade de transformações no interior da instituição, como uma melhor integração das relações intrainstitucionais e a ampliação da concepção de clínica. Mas, mesmo nesses casos, o psiquiatra continuou como o ponto de resistência à transição paradigmática. Ainda há por parte desse profissional pouca valorização dos espaços coletivos, e a clínica, apesar de ampliada, ainda é segmentada devido ao seu pouco engajamento nas novas propostas. Aqui já podemos falar de um conjunto de práticas, saberes, discursos e valores que se articulam em um conjunto significativo de transformações em oposição ao PPHM, ainda que se mantenha certa dependência em relação às internações psiquiátricas em Hospital Psiquiátrico, devido à ausência de leitos nos CAPS e ao tamanho reduzido das equipes, sinalizando um jogo de forças mais equilibrado.

Porém, alterações ainda mais intensas e profundas em sintonia com o PPS puderam ser encontradas naqueles municípios e instituições em que os CAPS integram políticas e estratégias de transformação mais amplas, promovidas em todo o campo da Saúde. Nesse caso, todas as mudanças já citadas ocorridas no interior da instituição são ampliadas e feitas de maneira ainda mais radical, com a participação da maioria dos profissionais. A integração dos CAPS ao todo da rede de assistência à Saúde parece ser o disparador para um processo de intensa exteriorização e territorialização da instituição, no sentido da ampliação e complexificação de suas variadas relações, tanto interinstitucionais, quanto transformando as relações com a população e com o Território para a formação de parcerias. Essas estratégias se mostraram potentes para intervir e modificar os modos de produção-reprodução da demanda, pois atuam de forma ampla, rizomática, no Território. Inevitavelmente, levam para fora do CAPS os processos de trabalho, toda a discussão e construção de uma nova ética, refletindo-se também na produção cultural e nos processos de subjetivação. Tais práticas e discursos por si já conseguem evitar o estrangulamento da instituição pela demanda por meio da corresponsabilização da produção da atenção nos variados âmbitos da rede assistencial, possibilitando a participação e integração dos profissionais do CAPS em outros espaços para a produção de cuidados no Território. É importante destacar que as equipes mais numerosas nos CAPS III favorecem essa estratégia. Isso ocorre em tamanha intensidade que o Hospital Psiquiátrico começa a ser percebido como exterioridade indesejada a essa mesma rede. Sua utilização é rara, restrita, preterida quase sempre em relação ao Hospital Geral, e motivo de embate e discórdia no planejamento das políticas públicas. Portanto, aqui podemos encontrar um conjunto de transformações que se opõem firmemente ao PPHM e conseguem superá-lo em muitos parâmetros do paradigma. Nesses casos podemos afirmar com clareza a presença da transição paradigmática.

Não nos permitimos falar em revolução paradigmática por entendermos que a Reforma Psiquiátrica deva se estender ainda a outras instituições de Saúde, não contempladas por esta pesquisa, e também devido as ainda persistentes discussões acerca das internações no Hospital Psiquiátrico. Mas, no contexto descrito acima em linhas gerais, é importante destacar que o processo se encaminha no sentido da transição paradigmática.

\section{Referências}

Amarante, P. (1995). Loucos pela vida: a trajetória da reforma psiquiátrica no Brasil. Rio de Janeiro: Fiocruz.

Amarante, P. (1996). O homem e a serpente. Rio de Janeiro: Fiocruz.

Amarante, P. (1999). Manicômio e loucura no final do século e do milênio. Em M. I. A. Fernandes, I. R. Scarcelli \& E. S. Costa (Orgs.), Fim do século, ainda manicômios? (pp. 47-53). São Paulo: IPUSP.

Birman, J., \& Costa, J. F. (1994). Organizações e instituições para uma psiquiátrica comunitária. Em P. Amarante (Org.), Psiquiatria social e reforma psiquiátrica (pp. 41-72). Rio de Janeiro: Fiocruz.

Cerqueira, L. (1984). Psiquiatria social: problemas brasileiros de saúde mental. Rio de Janeiro: Atheneu.

Costa, J. F. (1981). História da psiquiatria no Brasil. Rio de Janeiro: Campus.

Costa-Rosa, A. (1987). Saúde mental comunitária: análise dialética de um movimento alternativo. Dissertação de Mestrado, Universidade de São Paulo, São Paulo.

Costa-Rosa, A. (2000). O modo psicossocial: um paradigma das práticas substitutivas ao modo asilar. Em P. Amarante (Org.), Ensaios: subjetividade, saúde mental, sociedade (pp. 141-168). Rio de Janeiro: Fiocruz.

Costa-Rosa, A. (2006). A instituição de saúde mental como dispositivo social de produção de subjetividade [manuscrito não publicado]. Assis: UNESP.

Costa-Rosa, Luzio, C. A., \& Yasui, S. (2003). Atenção psicossocial: rumo a um novo paradigma na saúde mental coletiva. Em P. Amarante (Org.), Archivos de saúde mental e atenção psicossocial (pp. 12-25). Rio de Janeiro: Nau.

Devera, D. (2005). A reforma psiquiátrica no interior do estado de São Paulo: psiquiatria reformada ou mudança paradigmática? Dissertação de Mestrado, Universidade Estadual Paulista "Julio de Mesquita Filho", Assis.

Fleming, M. (1976). Ideologias e práticas psiquiátricas. Porto: Edições Afrontamento.

Kopnin, P. V. (1978). A dialética como lógica e teoria do conhecimento. Rio de Janeiro: Civilização Brasileira.

Kosik, K. (1976). Dialética do concreto. Rio de Janeiro: Paz e Terra. 
Luzio, C. A. (2003) A atenção em Saúde Mental em municípios de pequeno e médio portes: ressonâncias da Reforma Psiquiátrica. Tese de Doutorado, Universidade de Campinas, Campinas.

Minayo, M. C. de S. (2000). O desafio do conhecimento: pesquisa qualitativa em saúde. São Paulo: Hucitec.

Ministério da Saúde (2004). Legislação em Saúde Mental 19902004 (5ª . ed.). Brasília: Editora MS.

Pain, J. S., \& Almeida Filho, N. (2000). A crise da Saúde Pública e a utopia da Saúde Coletiva. Salvador: Casa da Qualidade.
Spink, M. J. P. (2000). Práticas discursivas e produção de sentidos no cotidiano: aproximações teóricas e metodológicas $\left(2^{\mathrm{a}}\right.$ ed.). São Paulo: Cortez.

Recebido em 22.07.08 Primeira decisão editorial em 19.08.09 Versão final em 01.09.09 Aceito em 03.09.09 